\title{
POSICIONAMENTO DE UM GRUPO DE ENFERMEIROS SOBRE O SEU COMPROMISSO SOCIAL
}

Doris E. Chaves, Ph.D.

\begin{tabular}{l|l|}
\cline { 2 - 2 } & ReBEn/02 \\
\hline
\end{tabular}

CHAVES, D.E. - Posicionamento de um grupo de enfermeiros sobre o seu compromisso social. Rev. Bras. Enf.; DF, 33 : 275-304, 1980

\section{INTRODUÇÃO}

O XXXI Congresso Brasileiro de Enfermagem apresentou como enfoque o posicionamento da profissão dentro da visão de responsabilidade da classe face à realidade nacional. As conferências, palestras e discussões serviram para questionar analiticamente o papel social da enfermagem, buscando uma maior coesão entre o papel profissional e as necessidades de saúde da população brasileira.

Conscientes da importância de tal posicionamento, as autoras de um dos subemas, "O Enfermeiro e seu Compromisso Social"," decidiram utilizar um instrumento de medida do conceito "compromisso social" com o objetivo de ajudar os enfermeiros participantes do congresso a se auto-avaliarem e refletirem sobre o nível de envolvimento com a realidade existente, projetando, para o futuro, modificações de sua conduta profissional.

Dentro deste propósito, o instrumento foi criado em duas partes: 1) método científico de questionar, com perguntas ou afirmações, operacionalizando elementos ou variáveis específicas das dimensões do compromisso social; e, 2) método de retroalimentação imediata para cada dimensão operacionalizada. Desta maneira, os enfermeiros, através de suas respostas, posicionavam-se em cada dimensão e, depois, obtinham o significado deste posicionamento em relação às expectativas teóricas de um perfil profissional caracterizado por compromisso social. (Questionário em anexo).

Com o intuito de aumentar a abrangência do impacto da metodologia, decidiram as autoras fazer um estudo do

* Subtema do Tema Oficial I, apresentado, em 6 de agosto de 1979, em Fortaleza, Cearń, tendo como autoras:

Maria Lúcia Ferreira Lima, M.S. - Professor Assistente, UFPe.

Maria Nilda de Andrade, M.S. - Professor Adjunto, UFPe.

Doris Emory Chaves, Ph.D. - Professor Visitante, UFPe. 
posicionamento do grupo. Para alcançar este propósito foi solicitado o retorno dos questionários depois de preenchidos. A distribuição dos questionários não seguiu um método aleatório, mas discriminou os profissionais que se fizeram presentes nas sessões plenárias do segundo, terceiro e quarto dias do Congresso, cobrindo somente enfermeiros. Um total de mil questionários, com a devida orientação para o preenchimento e devolução, foi distribuído durante as sessões do Congresso. Foram encontrados nas urnas de recolhimento, estrategicamente localizadas no saguão do Centro de Convenções, 207 questionários preenchidos.

O reduzido número de enfermeiros que sentiram o comprometimento inerente a um estudo analítico do posicionamento da classe frente ao compro.misso social indica serem os resultados aqui apresentados perfil de um grupo capaz de assumir o seu posicionamento e disposto a torná-lo público.

As autoras, conscientes da prestação de contas requerida pelo compromisso assumido, apresentam o perfil do grupo estudado para a reflexão dos profissionais.

\section{DIMENSÕES DO COMPROMIISSO SO- CIAL}

O desempenho do papel profissional não existe por si só. O papel profissional é parte do repertório de papéis e funções do indivíduo no contexto social. O comportamento que inclui a dimensão do compromisso social estabelece critérios para a tomada de decisão do profissional nas situações que requerem seletividade e hierarquização de alternativas. A decisão final deve compatibilizar as demandas em relação a tempo, energia, habilidades e valores pessoais exercidos sobre o profissional.
Em sua maior abrangência, o compromisso social refere-se à atitude manifestada pelo indivíduo em sua conduta face à realidade da sociedade. Neste estudo, essa atitude foi medida pela opinião expressa pelo enfermeiro ao selecionar a resposta aos itens apresentados. Estes abordavam as áreas de relacionamento do indivíduo consigo próprio e com outros, em termos do autoconceito profissional; relacionava o indivíduo com a classe e com o comportamento profissional, face às necessidades do HOMEM na coletividade local e nacional, e em situações cotidianas ou de emergências. As respostas presumiam ser possível um posicionamento em três opções:

1) uma aderência total, representada por agir daquela maneira "sempre" ou "concordar" com a afirmação;

2) uma aderência parcial, representada por agir daquela maneira "às vezes", ou "ter dúvidas" sobre a afirmação;

3) uma não aderência à ação ou comportamento, representada pela resposta "nunca", ou "não concorda".

As respostas omitidas foram adicionadas à última categoria, quando apropriado.

\section{MÉTODO DA APRESENTAÇÃO}

O procedimento adotado nesta apresentação segue uma seqüência lógica de pensamento, identificando e definindo a dimensão medida. A premissa de sustentação da dimensão é expressa, seguida da operacionalização dos seus elementos. Finalmente, a interpretação dos resultados é apresentada com apoio nos dados concretos. A expressão "a maioria dos respondentes" indica que mais de $70 \%$ dos enfermeiros escolheram aquela resposta. Em outros casos, o número específico é anotado. 
CHAVES, D.E. - Posicionamento de um grupo de enfermeiros sobre o seu compromisso s'ocial. Rev. Bras. Enf.; DF, $33: 275-304,1980$.

\section{APRESENTAÇÃO DO ESTUDO}

\section{Dimensão 1. Identidade Própria e Compromisso Social}

Definição: A identidade própria é o autoconceito do respondente, representado pelo comportamento escolhido em relação ao papel e o rótulo enfermeiro.

Premissa: Quando o indivíduo está satisfeito com o seu papel social, o seu autoconceito como profissional é elevado, a sua conduta demonstra o valor conferido ao rótulo, posição e funções relacionadas com aquela posição.

Operacionalização:

- estimula outros a seguirem o mesmo papel;

- apresenta-se em público dentro do autoconceito;

- encoraja membros do mesmc grupo a participar em atividades que valorizam o grupo.

Interpretação dos Resultados

Os enfermeiros indicam que, embora em sua maioria reconheçam e assumam o valor de sua posição profissional, existe um certo nível de ambivalência quanto ao autoconceito em termos da situação da profissão no âmbito social. Os respondentes procuram tornar a sua posição pública, mas não procuram recrutar familiares e amigos para se tornarem membros da profissão.

Uma das manifestações de um autoconceito elevado e de um alto nível de satisfação social com a posição ocupada na sociedade é o interesse de trazer novos adeptos à mesma posição, à mes ma maneira de pensar e de agir, dentro do contexto social. Dos respondentes, somente $54(26,08 \%)$ afirmam sempre aconselhar familiares e amigos a se tornarem enfermeiros, o que demonstra haver um nível alto de sentimentos ne- gativos à profissão dentro da valorização sócio-econômica e possivelmente cultural.

$\mathrm{Na}$ apresentação pública de sua pessoa, expondo não só a sua posição, mas também o seu papel social para outros, os respondentes demonstram um comportamento mais positivo (180: $86,95 \%$ ) $\mathrm{Na}$ sua maioria, os enfermeiros apresentaram respostas que indicam sempre optar por agir como estímulo a estudantes e outros grupos da comunidade, mostrando afirmar o valor da profissão a um público distanciado com maior freqüência do que o fazem ao seu grupo intimo.

Os comportamentos que estimulam e motivam a participação de colegas nas associações de classe foram escolhidos pela maioria dos respondentes (154: ' $14,39 \%)$. Quando as perguntas eram direcamente sobre a participaçāo ativa nos órgäos de classe, $188(90,82 \%)$ dos respondentes afirmam crer e assumir o compromisso com a classe, dizendo serem membros, e optarem por ações junto aos órgãos de classe. O mesmo não é demonstrado quando o comportamento questionado refere-se a uma escolha entre a atuação profissional e a participação em atividades junto a familiares. Um grupo limitado de respondentes (39: 18,84\%) afirmou uma supervalorização do papel profissional, escolhendo sempre atividades profissionais quando em competição com as atividades dos grupos familiares. Um mesmo número de enfermeiros afirma o oposto, demonstrando supervalorizar os papéis sociais de relacionamento familiar. Um número maior dos respondentes situou-se na opção de adesão parcial (120: $57,97 \%$ ) em situações de escolha entre atividades profissionais e familiares. Uma vez que a pergunta não especificava as condições sob as quais essa escolha deveria ser efetuada, podese afirmar que as respostas de adesão 
CHAVES, D.E. - Posicionamento de um grupo de enfermeiros sobre o seu compromisso Social. Rev. Bras. Enf.; DF, 33 : 275-304, 1980.

parcial desses respondentes foram apropriadas. O quesito não foi respondido por 9 enfermeiros.

A autodefinição que se caracteriza por possuir o componente compromisso social demonstra uma conduta deliberativa frente a demandas dos múltiplos grupos onde a pessoa participa. A tomada de decisão final, para o enfermeiro, requer uma ordem de valores à luz dos quais as situações são analisadas e prioridades definidas de acordo com as diferentes dimensões do compromisso social. A maioria dos enfermeiros estudados indica por suas opções estar consciente da conduta que requer avaliação da situação antes de assumir o papel mais apropriado.

Dimensão 2. Compromisso para com a Classe

Definição: Conhecimento dos dispositivos legais da profissão e reforçamento comportamental de suas diretrizes.

Premissa: Quando o indivíduo assume uma definição profissional em sua posição social, a sua conduta é guiada por conhecimento dos dispositivos legais da profissão e o seu comportamento reforça essas leis.

Operacionalização:

conhece e valriza os órgãos reguladores da profissão;

participa na avaliação dos regimentos legais em relação às mudanças sociais;

informa a sociedade sobre os regulamentos de sua função e zela pelo cumprimento da lei em seu ambiente de trabalho.

Interpretação dos Resultados

Um grupo de enfermeiros aqui representados (135: 65,21\%) demonstra aceitar o valor dos órgãos reguladores do exercício profissional, afirmando des- ta maneira o seu compromisso com o desenvolvimento sócio-econômico e político-legislativo da sociedade em relação ao reconhecimento da profissão no contexto social.

Reconhecer a profissão dentro da realidade do contexto social é um comportamento esperado do profissional, mesmo quando o conceito compromisso social não est́á em questão. Portanto, aderir parcialmente, ou não aderir às perguntas que indicam o valor dos órgãos reguladores do exercício profissional é contrário ao compromisso para com a classe. Dos respondentes, 71 $(34,29 \%)$ expressam esta posição, indicando não definir a profissão como um dos grupos regulamentados pela sociedade e por si próprio.

No entanto, a maioria dos enfermeiros (189: 91,30\%) concorda com a afirmação de ser o profissional responsável por examinar e opinar sobre a lei em relação às mudanças sociais, como também a maioria (196: 94,68\%) concorda que informar sobre os regulamentos e zelar pelo cumprimento destes, é responsabilidade do profissional.

Embora o grupo de enfermeiros estudados apresente um perfil de dúvida quanto à profissão na realidade social, em sua maioria os respondentes apresentam um compromisso individual para com a profissão, representado pelas afirmações de responsabilidade de zelar pelo exercício profissional e participar na formulação de leis.

Dimensão 3. Posicionamento Próprio na Atuação Cotidiana

Definição: Delimitação de papel na atuação profissional individual e em equipe para minorar desigualdades de serviço.

Premissa: Quando o profissional está seguro em sua autodefinição, ele é capaz de avaliar as demandas sociais 
CHAVES, D.E. - Posicionamento de um grupo de enfermeiros sobre o seu compromisso social. Rev. Bras. Enf.; DF, 33 : 275-304, 1980.

sobre a sua função, e de definir o seu campo de ação dentro desta realidade, sempre considerando a clientela sem discriminação.

Operacionalização:

- nível de autonomia assumida na definição do campo de atuação;

- nível de conscientização das desigualdades sociais influenciando serviços prestados.

Interpretação dos Dados

As respostas dos enfermeiros nas questões que mediram esta dimensão indicam que a autonomia profissional do grupo ainda não está bastante assegurada, mesmo quando a definição da situação de desigualdade é reconhecida e não aceita. A atuação cotidiana dos enfermeiros estudados continua a vacilar entre um modelo de subjugação administrativa e de autonomia profissional. Quando interrogados sobre execução de ações decididas por outros e planejadas pelo poder executivo da instituição $87(42,02 \%)$ afirmam só executá-las depois de estudarem as decisões, enquanto $34 \quad(16,49 \%)$ executam sem questionar ações decididas por outros. Os respondentes que executam ordens sem questionamento : estão se posicionando em uma subjugação administrativa, perdendo a valorização de um profissional autônomo.

A maioria dos respondentes (170: $82,12 \%$ ) observa e não aceita as desigualdades na qualidade de serviço, afirmando também executar as ações que são planejadas por iniciativa própria com o fim de melhorar as desigualdades do serviço.

Quando questionados sobre quem delimita o seu papel nas ações já planejadas, pn ıvalece a atitude autônoma. No entanto, $113(54,58 \%)$ respondentes aceitam assumir de imediato as ações delegadas ou solicitadas por outros, in- dicando uma forte persistência da ambivalência na definição de autonomia profissional.

Quando o propósito da ação é alcançar mudanças em situações de desigualdade na qualidade dos serviços, um grupo dos respondentes (120: 57,97\%) tende a se refugiar na tecnologia e nas ações espcíficas de enfermagem. No entanto, um grupo maior (145: $70,24 \%$ ) escolhe respostas que descrevem ações em equipe.

O grupo de enfermeiros estudados demonstra um alto nível de ambivalência quanto à autodefinição do compromisso social na atuação cotidiana em relação às desigualdades sociais, e à autonomia de ação. As respostas dos respondentes mostram ser a tecnologia específica de enfermagem um campo seguro de ação. Do mesmo modo, ações iniciadas e planejadas pelo enfermeiro não encontram dificuldades ou dúvidas quanto à responsabilidade própria de execução. A ambivalência aparece quando o enfermeiro precisa considerar e escolher entre atuação puramente profissional e aquela que é requerida para satisfazer o poder administrativo. Este dilema de autodefinição demonstra certa dificuldade de adesão ao compromisso social face às populações menos privilegiadas, as quais recebem tratamento diferenciado nos sistemas de saúde.

Dimensão 4. Percepção da Necessidade de Buscar uma Compreensão Crítica da Realidade

Definição: Abrangência da definição social da comunidade de trabalho.

Premissa: Quando o profissional assume o compromisso social da profissão, ele conhece o sistema empregador e avalia as condições de vida da população com a qual trabalha.

Operacionalização: 
CHAVES, D.E. - Posicionamento de um grıpo de enfermeirss sobre o seu compromissı S'rial. Rev. Bras. Enf.; DF, 33 : 275-304, 1980.

- conhece a organização do sistema empregador;

- relaciona o sistema com as condiçōes municipais e outros recursos de saúde;

- atua profissionalmente na comunidade.

Interpretação dos Resultados

Um dos libelos apresentados contra o protissional de enfermagem é o de estar este distanciado ou alienado dentro do sistema onde trabalha, sendo mesmo acusado de desconhecer não só o seu papel, mas o sistema que regula a execução desse papel. Os resultados obtidos do grupo de enfermeiros no estudo indicam o contrário: dos 207 respondentes, 200 afirmam assumir a responsabilidade de conhecer o sistema onde trabalham. A maioria afirma assumir em seu comportamento habitual uma expansão maior de sua visão e conhecimento, relacionando o sistema de trabalho com o município e outros recursos de saúde; o mesmo número (173: $83,57 \%$ ) afirma procurar conhecer também as condiçōes de vida da população.

Os itens que questionam o nível de ação direta com a comunidade induz a uma distribuição menos homogênea. Quando as perguntas se referem a trabalho na comunidade dentro do encargo profissional, $134(64,73 \%)$ dos respondentes afirmam sempre escolher uma participação ativa. No entanto, quando questionados sobre a participação individual na comunidade fora da área empregatícia, $95 \quad(45,89 \%)$ afirmam sempre assumir esta atitude e 91 $(43,93 \%)$ o fazem às vezes.

Os enfermeiros estudados, portanto, assumem o compromisso de compreender a realidade de trabalho e da população servida. No entanto, o compromisso social para com esta população é uma função direta do âmbito de trabalho, indicando que o compromisso social abrangente ainda é limitado.

Dimensão 5. Interesse pela Realidade da Classe e da Coletividade Nacional

Definição: Abrangência das fontes de informação utilizadas para suprir conhecimento do papel profissional e da realidade nacional e abrangência do interesse na temática da sociedade.

Premissa: Quando o profissional assume o compromisso social, ele assume também um comportamento ativo le busca e de informação sobre a realidade com a qual atua e sobre o conhecimento científico que apóia a sua função profissional, envolvendo-se com os temas da sociedade em que vive.

Operacionalização:

- utiliza periódicos profissionais nacionais e estrangeiros;

- utiliza periódicos informativos sobre a profissão e sobre assuntos de abrangência nacional e internacional;

- participa de congressos e reuniōes científicas;

- expressa interesse nas temáticas político-sócio-culturais, técnico-científicas e de grupos especíticos.

Interpretação dos Resultados

Os periódicos profissionais de tiragem nacional são utilizados sempre por $143(69,08 \%)$ dos respondentes, com exceção de periódicos que têm características regionais, onde a escolha varia de $21(10,14 \%)$ a $117(57,48 \%)$. Quando as publicações são de notícias sobre enfermagem, 148 (71,49\%) dos respondentes sempre as utilizam, indicando ser o grupo estudado interessado em conhecer os acontecimentos nacionais da profissão. Este nível de interesse não 
CHAVES, D.E. - Posicionamento de um grupo de enfermeiros sobre o seu compromisso social. Rev. Bras. Enf.; DF, 33 : 275-304, 1980.

é mantido quando a pergunta se refere a periódicos estrangeiros. Somente 24 $(11,65 \%)$ dos respondentes utilizam sempre publicações internacionais, enquanto que $86(41,74 \%)$ nunca utilizam essa referência. Estes fatos indicam ser o grupo de respondentes, em sua maioria, ativos na busca de conhecimentos, sem necessariamente assumirem o compromisso de conhecer outras línguas que os ajudem a relacionar o desenvolvimento científico nacional com aqueles já adquiridos por outros países.

Esta perspectiva selecionadora do interesse é também refletido nas respostas referentes ao nível de interesse por temas da realidade brasileira. Os temas e assuntos de controvérsia política ou de significado para grupos específicos em outras classes do contexto social não recebem a mesma aderência dos temas gerais e diretamente relacionados com a profissão. Por exemplo, enquanto que temas econômicos, culturais e técnico-científicos foram escolhidos como de grande interesse por 173 $(83,57 \%)$ ou mais dos respondentes, a temática partidária, feminista, grevista, e problemas de anistia e índios foi considerada de grande interesse por 80 $(38,64 \%)$ ou menos dos respondentes.

Pode-se inferir que o grupo de enfermeiros estudados representa uma população interessada na realidade que exerce uma influência direta no seu papel profissional, ou que é definida como uma realidade do seu ambiente mais próximo. Portanto, o compromisso social do grupo em relação à atitude de interesse pela realidade social e científica da profissão possui uma característica nacionalista e provincialista.

Dimensão 6. Posicionamento P r ó p rio Face aos Problemas da Comunidade

Definição: Nível de conscientização das desigualdades sociais da comunidade onde vive.
Premissa: O profissional que possui compromisso social reconhece as desigualdades sociais e questiona o impacto destas sobre a população.

Operacionalização:

- questiona o nível de vida, educação, poder aquisitivo e potencial de trabalho da população;

- questiona as condições de vida das crianças;

- questiona condições de saúde da população.

\section{Interpretação dos Resultados}

Esta dimensão, medida por perguntas hipotéticas de autoquestionamento frente à realidade observada, demonstra, através da análise dos dados, que os enfermeiros respondentes representam uma população homogênea no comportamento escolhido. Em sua maioria, os enfermeiros nunca deixam de questionar as desigualdades das condições de vida da população na comunidade onde vivem.

Sendo o número de respondentes 207, e o número de perguntas 13 , seria possível obter um total de 2.691 respostas. Das respostas obtidas, 2.230 $(82,56 \%)$ afirmam sempre questionar a realidade, enquanto que $40(1,48 \%)$ dizem nunca questionar as desigualdades. O número restante de respostas foi deixado em branco, ou por falta de interesse ou por serem esses respondentes alienados à realidade social que os cerca.

Dimensão 7. N í vel de Envolvimento com a Comunidade Dentro da Realidade Existente

Definição: Tipo de atuação profissional em relação às populações marginalizadas da comunidade onde vive.

Premissa: Quando o profissional assume o compromisso social, ele não 
CHAVES, D.E. - Posicionamento de um grupo de enfermeiros sobre o seu compromisso social. Rev. Bras. Enf.; DF, 33 : 275-304, 1980.

só questiona as desigualdades sociais, mas assume um papel ativo na melhoria das condições de vida e de saúde das populações marginalizadas.

Operacionalização:

- níveis de ações individuais, caritativas e solucionadoras de problemas;

- níveis de ações de grupo, como membro da classe profissional e como cidadão do contexto, na solução de problemas.

Interpretação dos Resultados

Os enfermeiros estudados apresentam em sua maioria a característica do compromisso social junto aos grupos marginalizados da comunidade, dentro das dimensões de soluções de problemas em ações individuais e em grupos. O grupo de enfermeiros aqui representados utiliza pouco o comportamento caritativo, indicando usar a autodefinição profissional na escolha das respostas. Nas ações individuais, os respondentes demonstram um comportamento de atitude científica de observação direta da problemática (184: $88,88 \%$ ) e de análise da situação (179: $86,47 \%$ ). Quanto à participação em ações de grupo, a aderência total foi confirmada por $185(89,37 \%)$, nas ações como representante da classe, e por 190 $(91,78 \%)$, nas ações junto a grupos da comunidade para a solução dos problemas; esta escolha demonstra uma atitude coerente com a definição do compromisso social na sua expansão de abrangência comunitária.

Dimensão 8. Compromisso Social em Situações de Risco para a Comunidade

Definição: Nível de atuação profissional em situações de emergência pública.
Premissa: Quando o profissional assume o compromisso social, ele se define como um recurso disponível em situações de calamidade ou emergência sócio-político-econômicas.

Operacionalização:

- tipo de participação: passiva ou tiva;

- nível de atuação na Escala de Integração.

Interpretação dos Resultados

Esta dimensão foi medida dentro de um conceito de participação em relação a uma escala teoricamente estabelecida pelas autoridades, compreendendo uma seqüência comportamental que demonstra atitudes de integração do compromisso social numa seqüência multidimensional. As variáveis desta escala foram derivadas da teoria de valores 1 descrevendo a característica do respondente da seguinte maneira: 1) sensibilizado; 2) conscientizado; 3) motivado; e 4) integrado, na forma de participação passiva e ativa.

O grupo de enfermeiros estudado demonstra optar por respostas de aderência total nos itens de participação passiva, na razão inversa do nível de integração.

O indivíduo que está passivamente sensibilizado atenta para a realidade, mas não age diretamente sobre ela. Dos respondentes, $199(96,13 \%)$ assumem esta atitude sempre quando há situações de risco e emergência na comunidade. Os indivíduos conscientizados analisam a situação e referem a realidade a algum princípio científico ou valorativo. Quando a atitude é passiva, a pessoa não age sobre a sua própria conclusão. Dos respondentes, $168(81,15 \%)$ assumem esta atitude. O nível motivado implica em organizar ou planejar ações para minorar as dificuldades. Quando a pessoa está motivada, mas 
CHAVES, D.E. - Posicionamento de um grupo de enfermeiros sobre o seu compromisso social. Rev. Bras. Enf.; DF, 33 : 275-304, 1980.

assume a atitude passiva, o seu comportamento indica uma atuação indireta, isto é, participa com outros no planejamento, mas não inicia as ações. Dos enfermeiros estudados, $127(61,35 \%)$ indicaram assumir essa atitude, o mesmo número indicou a atitude passiva do nível integrado que demonstra ações dirigidas à população flagelada, através de organizações e trabalho de equipe.

A participação ativa que requer uma participação mais direta a cada nível obteve um menor número de adesões em todos os níveis. No entanto, a sequêencia lógica, teoricamente definida, não foi demonstrada nos resultados, isto é, não houve uma relação inversa do número de adesões ao nível de integração. O nível que desviou os resultados dessa concordância teórica foi 0 conscientizado ativo. Por exemplo, o nível de sensibilizado ativo recebeu 126 $(60,86 \%)$ de adesões totais àquela conduta, enquanto que o nível de conscientizado recebeu $97(46,85 \%)$, o nível motivado $117(56,52 \%)$ e o integrado 107 $(51,69 \%)$.

Como os resultados na variável de comportamento conscientizado não seguem a proposição teórica, o seu conteúdo foi analisado para obter uma explicação. Verifica-se que este item descreve um comportamento ativo de busca de informação visitando a área flagelada. Enquanto os outros itens ativos aproximam-se dos comportamentos usualmente executados pelo enfermeiro na área de tecnologia ou trabalho em equipe, o desvio da seqüência lógica pode ser explicado como tendo sofrido uma interferência dos outros papéis sociais dos respondentes, principalmente em relação à posição da mulher no con-texto da sociedade. Este fato indica que, embora não explícito, o posicionamento do enfermeiro nas dimensões do compromisso social requer uma hierarquia de valores onde os papéis profissionais possam ser separados das definições da pessoa em relação aos outros papéis assumidos. O grupo estudado demonstra ter iniciado esta tarefa difícil, em sua maioria assumindo o compromisso social face a situações de risco da comunidade nas atitudes passivas, mas diminuindo o número de adesões totais à medida que os comportamentos esperados envolvem um compromisso total. Nas atitudes ativas, o nivel de participação junto à realidade encontrou adesão menor dos respondentes, indicando haver certa dúvida sobre o papel profissional e a definição cultural do papel social da pessoa face a certas dificuldades da população em risco. Este fato demonstra estar o grupo de enfermeiros com uma autodefinição menos profissional do que social, nas situações que requerem escolha de conduta.

\section{SUMÁRIO}

O estudo propôs posicionar o grupo de enfermeiros, participantes do XXXI Congresso Nacional de Enfermagem, nas dimensões do compromisso social medidas em um questionário de autoavaliação.

De um mil questionários distribuídos, somente 207 foram devolvidos, o que indica serem esses enfermeiros um grupo sui generis, não sendo possível considerar os resultados como representativos da enfermagem brasileira.

Os enfermeiros estudados, em sua maioria, apresentam um perfil de compromisso social nas dimensões definidas. A maioria dos respondentes valoriza a profissão publicamente, mas nem sempre deseja que familiares e amigos sigam o seu exemplo; são ativos na busca de informação sobre a profissão e a coletividade nacional, dentro de uma perspectiva nacionalista e provincialista. O grupo demonstra assumir um pa- 
CHAVES, D.E. - Posicionamento de um grupo de enfermeiros sobre o seu compromisso social. Rev. Bras. Enf.; DF, 33 : 275-304, 1980.

pel profissional frente às desigualdades sociais e possíveis calamidades pública, mas demonstra ambivalência quanto à sua autonomia profissional. O perfil apresenta, também, limitações na atuação que requer expansão do papel pro- fissional a um maior envolvimento com o desenvolvimento social, mostrando certa dificuldade na separação do comportamento profissional em relação a outros compromissos pessoais no ambiente sócio-cultural.

\section{B I B L I O G R A F I A}

1. CHAVES, Doris Emory. Enfermagem; qual a sua direçāo? Recife, 1978. 15 f. Mimeografado. Apresentado no Simpósio Comemorativo da Sema- na da Enfermagem, realizado na UFPE, 1978.

2. SMITH, Brewster M. Social psychology and human values. Chicago, University of Chicago Press, 1969. 
CHAVES, D.E. - Posicionamento de um grupe de enfermeiros sobre o seu compromisso Social. Rev. Bras. Enf.; DF, 33 : 275-304, 1980.

\title{
O COMPROMISSO SOCIAL DO ENFERMEIRO *
}

\author{
QUESTIONÃRIO DE AUTO-AVALIAÇÃO \\ Instruções Gerais para Preenchimento
}

NESTE QUESTIONÁRIO NÃO EXISTEM RESPOSTAS CERTAS OU
ERRADAS

TODOS OS ITENS LEVAM A UMA IDENTIFICAÇĀO DO SEU POSICIONAMENTO EM CADA DIMENSÃO DO COMPROMISSO SOCIAL APRESENTADA. TODOS OS ITENS SÃO IMPORTANTES PARA UMA AUTO-AVALIAÇÃO.

\section{NĀO DEIXE NENHUM ITEM EM BRANCO VOCE NÃO SERA IDENTIFICADO}

NA PRIMEIRA PÁGINA ESTÃO OS DADOS PESSOAIS PARA ANALISE QUE NĀO REQUEREM EXPLICAÇÃO. NAS PAGINAS SEGUINTES, O QUESTIONÁRIO CONTEM NUMA PAGINA OS ITENS REFERENTES A UMA DIMENSĀO DO COMPROMISSO SOCIAL E NOUTRA, A FORMA DE AVALIAR OS ITENS.

\section{LEIA CADA ITEM ATENCIOSAMENTE ANTES DE ASSINALAR A SUA RESPOSTA}

SOMENTE APOS ASSINALAR TODOS OS ITENS EM CADA PAGINA, VOCE PROCURARÁ NA PAGINA SEGUINTE A FORMA DE AUTOMEDIR-SE. PARA CADA CONJUNTO DE DUAS PAGINAS (DIMENSÃO E MEDIDA), O PROCEDIMENTO SERÁ O MESMO.

\footnotetext{
* Questionário elaborado por: Doris Emory Chaves, Ph.D. - Professor Visitante, UFPe. Maria Lúcia Ferreira Lima, M.S. - Professor Assistente, UFPe. Maria Nilda de Andrade, M.S. - Professor Adjunto, UFPe.
} 
CHAVES, D.E. - Posicionamento de um grupo de enfermeiros sobre o seu compromisso s.ocial. Rev. Bras. Enf.; DF, 33 : 275-304, 1980.

\section{IDENTIFICAÇÃO}

Idade: Anos: Sexo: $\quad$ Estado civil:

Natureza da instituição onde trabalha:

serviço

ensino

ambos

PRINCIPAL ÁREA DE ATUAÇÃO

- Enfermagem Médico-Cirúrgica (incluindo Introdução à Enfermagem)

- Enfermagem Materno-Infantil

- Enfermagem de Saúde Pública

- Saúde Mental (incluindo Enfermagem Psiquiátrica)

- Administração

- Didática Aplicada à Enfermagem (incluindo responsabilidade de treinamento de pessoal e/ou ensino da disciplina específica)

EXERCICIO PROFISSIONAL EM ANOS:

- menos de 5 anos

- 5- 9 anos

- $10-14$ anos

- 15 - 19 anos

- 20 ou mais anos

TITULAÇO ACADEMICA:

- Graduação (incluindo habilitação)

- Pós-graduação lato sensu (Atualização, Aperfeiçoamento e Especialização)

- Pós-graduação stricto sensu (Mestrado, Doutorado e Livre Docência) 
CHAVES, D.E. - Posicionamento de um grupo de enfermeiros sobre o seu compromisso social. Rev. Bras. Enf.; DF, 33 : 275-304, 1980.

Mesmo que você nunca tenha experimentado uma situação semelhante, marque na coluna à direita o que neste momento pensa. Quando solicitado, você decide:

\section{Sempre As vezes Nunca}

1. Estimular a opção de filhos de amigos e parentes a seguirem enfermagem como profissão.

2. Aceitar a responsabilidade de apresentar enfermagem a um grupo de estudantes ginasiais.

3. Fazer palestras sobre enfermagem em grupos fora da área de saúde.

4. Preencher fichas pessoais em hotéis ou reuniões fora da área de saúde, escrevendo a palavra enfermeiro no lugar reservado ao registro da profissão.

5. Participar como sócio da Associação Brasileira de Enfermagem.

6. Aceitar de boa vontade os encargos atribuídos a você pelas associações de classe.

7. Encorajar os colegas a envolverem-se nos órgãos de classe.

8. Escolher participar dos CORENs mesmo que não fosse compulsório.

9. Escolher participar de grupos sociais e de interesse de sua familia antes de atuar em grupos específicos de enfermagem. 
CHAVES, D.E. - Posicionamento de um grupo de enfermeiros sobre o seu compromisso social. Rev. Bras. Enf.; DF, 33 : 275-304, 1980.

\section{IDENTIDADE PRÓPRIA E COMPROMISSO SOCIAL}

Se as suas respostas aos itens 1, 2, 3 e 4 caíram na coluna de "SEMPRE", você está disposto a manifestar publicamente sua identidade profissional.

Se as suas respostas aos itens 5, 6, 7 e 8 caíram na coluna de "SEMPRE", você manifesta claramente seu compromisso com sua classe profissional.

Se sua resposta ao item 9 caiu na coluna de "SEMPRE", a sua prioridade de compromisso e sua identidade própria, estão fora da profissão.

Se suas respostas aos itens de 1 a 8 caíram na coluna de "SEMPRE", você pode se considerar um profissional identificado e comprometido com sua profissão num nível excelente.

Se 5 de suas respostas (aos itens de 1 a 8) caíram na categoria "SEMPRE", você encontra-se num nível aceitável de compromisso e identidade com sua profissão.

Se, porém, 5 de suas respostas caíram na categoria "AS VEZES", sua identidade profissional e seu compromisso para com a profissão estão num nivel não satisfatório. Reflita mais sobre VOCÊ e SUA PROFISSĀO. 
CHAVES, D.E. - Posicionamento de um grupo de enfermeiros sobre o seu compromisso social. Rev. Bras. Enf.; DF, 33 : 275-304, 1980.

Em relação às afirmativas acerca da criação do COFEN-CORENs e da Lei do Exercício Profissional, você:

\section{Concorda Em dúvida Discorda}

1. A criação do COFEN-CORENs representou um passo importante para assegurar o posicionamento da profissão de Enfermagem.

2. A existência do COFEN-CORENs é essencial para controle do exercício profissional.

3. Conhecer a lei do exercício profissional é essencial para a atuação profissional.

4. Examinar a lei do exercício profissional com vista a introduzir modificações é responsabilidade de todo enfermeiro.

5. Opinar sobre a lei do exercício profissional é um direito e um dever de cada enfermeiro.

6. Prestar esclarecimentos acerca da lei do exercício profissional é responsabilidade de todo enfermeiro.

7. Zelar pelo cumprimento da lei do exercício profissional é responsabilidade de todo enfermeiro. 
CHAVES, D.E. - Posicionamento de um grupo de enfermeiros sobre o seu compromiss? s.ocial. Rev. Bras. Enf.; DF, 33 : 275-304, 1980.

\section{COMPROMISSO PARA COM A CLASSE}

Se você assinalou na coluna "CONCORDA" para todos os itens, seu compromisso para com a sua classe profissional está no nível EXCELENTE.

Se você assinalou na coluna de "CONCORDA" para 3 a 5 itens, seu compromisso social está no nível ACEITÁVEL.

Se você assnalou "CONCORDA" para menos de 3 itens, seu compromisso social está no nível BAIXO.

Se você assinalou todos os itens na coluna "DISCORDA", você está ALIENADO em relação ao compromisso com sua classe profissional. Reflita sobre os motivos que o levaram a tal posicionamento! Você é responsável pela definição de si mesmo e pelo destino de sua classe profissional!

Se você assinalou "EM DÚVIDA" para todos os itens, você necessita buscar informações sobre sua classe para poder posicionar-se em relação à legislação do exercício profissional. 
CHAVES, D.E. - Posicionamento de um grupo de enfermeiros sobre o seu compromisso social. Rev. Bras. Enî.; DF, 33 : 275-304, 1980.

Quando em sua atuação profissional cotidiana, você:

Sempre Às vezes Nunca

1. Observa e não aceita as desigualdades existentes na qualidade de assistência à clientela, com o mesmo problema de saúde.

2. Observa e aceita os níveis desiguais de assistência à clientela.

3. Analisa e delimita ação própria na atuação profissional, antes de assumir o seu papel.

4. Assume de imediato as ações a você delegadas ou de você solicitadas no seu papel profissional.

5. Convoca outros profissionais para ação conjunta na mudança de situações de desigualdades.

6. Concentra-se na atuação própria e no desempenho individual eficiente dentro da tecnologia específica de Enfermagem.

7. Executa ações planejadas por iniciativa própria para ajudar a modificação do sistema de saúde quando necessário.

8. Executa ações decididas pelo Executivo. colaborando em mudanças planejadas pelas autoridades, sem questioná-las. 
CHAVES, D.E. - Posicionamento de um grupo de enfermeiros sobre o seu compromisso social. Rev. Bras. Enf.; DF, 33 : 275-304, 1980.

\section{POSICIONAMENTO PRÓPRIO NA ATUAÇÃO COTIDIANA}

Se você assinalou os itens números (1, 3, 5, 7) na coluna "SEMPRE", o seu compromisso social em sua atuação cotidiana é EXCELENTE.

Se você assinalou os itens pares na coluna "SEMPRE", o seu compromiss $\odot$ social é reduzido.

Se você assinalou 3 ou mais itens, pares ou impares, na coluna "ÀS VEZES", seu posicionamento em relação ao compromisso social não está claramente definido.

Analise os seus valores pessoais e profissionais e decida qual a orientação a seguir. Lembre-se, os valores devem estar coerentes com as ações! 
CHAVES, D.E. - Posicionamento de um grupo de enfermeiros sobre o seu compromisso S'Jcial. Rev. Bras. Enf.; DF, $33: 275-304,1980$.

Se você for designado para trabalhar em determinado lugar, você:

Sempre As vezes Nunca

1. Procura conhecer o sistema para onde foi designado.

2. Procura conhecer as condições do município em relação aos recursos de saúde e saneamento básico existentes.

3. Procura conhecer as condições de vida da população, em relação a poder aqui. sitivo, habilitação, nível de educação, tradições, crenças, valores, politização.

4. Procura situar o município do contexto sócio-sanitário do país.

5. Limita sua atuação a executar muito bem suas tarefas dentro do sistema de saúde.

6. Aceita outros encargos na comunidade, fora de seu ambiente de trabalho.

7. Inicia um trabalho na comunidade, mobilizando a participação das esferas sociais e recursos existentes. 
CHAVES, D.E. - Posicionamento de um grupo de enfermeiros sobre o seu compromisso social. Rev. Bras. Enf.; DF, 33 : 275-304, 1980.

\section{PERCEPÇÃO DA NECESSIDADE DE BUSCAR UMA COMPREENSÃO CRITICA DA REALIDADE}

Se ao responder os itens $1,2,3$ e 4 você assinalou na coluna "SEMPRE", seu nível de percepção da necessidade de buscar uma ampla compreensão crítica da realidade está EXCELENTE.

Se, porém, você assinalou para dois cios itens acima citados nas colunas "ÀS VEZES" e "NUNCA", seu nível de percepção da necessidade de buscar uma compreensão crítica da realidade é ACEITÁVEL.

Se assinalou apenas um, entre os itens 1, 2, 3 e 4 na coluna "SEMPRE", você necessita refletir mais e melhor em torno da realidade social à sua volta. Cuidado, você está a um passo da ALIE r̛̃aÇÃO!

Se você assinalou na coluna "SEMPRE" ao responder o item 5, sua percepção da necessidade de buscar uma compreensão crítica da realidade é quase nula em conseqüência, assim também é seu compromisso social. (Este pode ser reduzido a um nível muito baixo).

\section{PERCEPÇÃO DA RESPONSABILIDADE PRÓPRIA PARA COM A COMUNIDADE}

Se você assinalou na coluna "SEMPRE" ao responder os itens 6 e 7, seu nível de percepção de sua responsabilidade pessoal para com a comunidade (essencial no compromisso social) é EXCELENTE. Se você assinalou apenas um dos dois itens na coluna "SEMPRE", você está no nível ACEITÁVEL em relação à sua responsabilidade para com a comunidade.

Se, porèm, você respondeu para os dois itens (6 e 7) "ÀS VEZES", seu nível de responsabilidade para com a comunidade é reduzido. Atenção, reflita sobre seu compromisso social!

Se você respondeu "NUNCA" para os dois itens citados, você é um individualista e desconhece o que seja compromisso social. 
CHAVES, D.E. - Posicionamento de um grupo de enfermeiros sobre o seu compromisso s.ocial. Rev. Bras. Enf.; DF, 33 : 275-304, 1980.

\section{REALIDADE DA CLASSE PROFISSIONAL E DA COLETIVIDADE NACIONAL}

Se você assinalou "SEMPRE" para todos os itens (de 1 a 12), você está num nível EXCELENTE de interesse pela busca de compreensão crítica da realidade de sua classe profissional e de seu país.

Se você assinalou 6 a 8 dos itens nas colunas "SEMPRE" e "RARAMENTE", você está num nivel ACEITÁVEL de interesse pela realidade de sua profissão e de seu pais.

Se você assinalou menos de 6 ítens nas colunas "SEMPRE" e "ÀS VEZES", seu interesse pela realidade de sua classe e de seu país está reduzido. Você deve reconsiderar seu posicionamento face o compromisso social!

Para situar seu posicionamento em relação ao interesse pela realidade de sua classe profissional e pela realidade de seu país, isoladamente, compare suas respostas abaixo dìscriminadas:

Itens 1 a 7: Interesse pela realidade da classe profissional Medidas:

Nível EXCELENTE - se assinalou "SEMPRE" para todos os itens.

Nível ACEITÁVEL — se assinalou "SEMPRE” ou "RARAMENTE" para 4 ou mais. dos itens.

Nível BAIXO - se assinalou menos de 4 itens nas colunas "SEMPRE" e "ÀS VEZES".

Itens 8 a 12: Interesse pela realidade social do pais

Nível EXCELENTE - se assinalou “SEMPRE” para todos os itens.

Nível ACEITÁVEL - se assinalou "SEMPRE" ou "RARAMENTE" para 3 ou mais itens desta categoria.

Nível BAIXO - se assinalou menos de 3 itens nas colunas "SEMPRE" e "ÀS VEZES". 
CHAVES, D.E. - Posicionamento de um grupo de enfermeiros sobre o seu compromisso social. Rev. Bras. Enf.; DF, 33 : 275-304, 1980.

Indique com que freqüência você utiliza as seguintes fontes de informação acerca das realidades atuais de sua classe profissional e da coletividade como lm todo:

1. Revista Brasileira de Sempre Às vezes Nunca Enfermagem

2. Enfermagem em Novas Dimensões

\section{Enfermagem Atual}

4. Revista Gaúcha de Enfermagem

5. Jornal de Enfermagem

6. Periódicos estrangeiros de Enfermagem

7. Congressos e outras reuniões científicas na área de Enfermagem

8. Noticiário TV

9. Jornal

10. Revista (tipo Manchete, Visão e semelhantes)

11. Teatro

12. Conferências ou reuniôes de debate acerca de aspectos da realidade brasileira. 
CHAVES, D.E. - Posicionamento de um grupo de enfermeiros sobre o seu compromisso social. Rev. Bras. Enf.; DF, 33 : 275-304, 1980.

Em relação aos temas da atualidade na sociedade brasileira, o seu nível de interesse é:

Grande Pouco Nenhum

1. Economia nacional

2. Política partidária nacional

3. Índio brasileiro

4. Cultura brasileira

5. Educação brasileira

6. Anistia aos punidos

Revolução de 1964

7. Movimentos grevistas

8. Movimento feminista

9. Movimento artístico brasileiro

10. Movimento técnico-científico brasileiro

11. Ação social da Igreja no país

12. Petróleo e racionamento de combustível

13. Problemática de saúde. 
CHAVES, D.E. - Posicionamento de um grupo de enfermeiros sobre o seu compromisso social. Rev. Bras. Enf.; DF, 33 : 275-304, 1980.

\section{INTERESSE PELA REALIDADE NACIONAL}

Se assinalou de 8 itens a mais na coluna "GRANDE INTERESSE", você pode considerar-se um profissional comprometido na busca de compreensão da realidade, comportamento este essencial para assumir o compromisso social.

Se este nível não foi alcançado, você necessita refletir mais acerca da realidade nacional e reconsiderar seu posicionamento face o compromisso social. 
CHAVES, D.E. - Posicionamento de um grupo de enfermeiros sobre o seu compromisso social. Rev. Bras. Enf.; DF, 33 : 275-304, 1980.

Ao passar em frente a um grupo populacional marginalizado (aglomerado de casebres, favelas, mocambos, "invasões", etc.) de sua comunidade, você se questiona:

Sempre As vezes Nunca

1. Como sobrevivem estas pessoas?

2. Como pensam estas pessoas?

3. Quantas crianças estão abandonadas?

4. Como conseguem alimentos e trabalho?

5. Quantos estão em idade de trabalho?

6. Como tratam das crianças?

7. Quantos analfabetos existem?

8. Como resolvem seus problemas de saúde?

9. Quantas crianças freqüentam a escola?

10. A quem recorrem estas pessoas para auxílio?

11. De onde vem a água que consomem?

12. Que destino dão ao lixo e dejetos?

13. Quais os fatores contribuintes para esta situação? 
CHAVES, D.E. - Posicionamento de um grupo de enfermeiros sobre o seu compromisso social. Rev. Bras. Enf.; DF, 33 : 275-304, 1980.

\section{POSICIONAMENTO PRÓPRIO FACE AOS PROBLEMAS DA COMUNIDADE}

Se assinalou 6 ou mais itens da coluna "SEMPRE", você está num nível EXCELENTE de sensibilização pelos problemas da comunidade.

Se, no entanto, poucas ou nenhuma destas perguntas lhe ocorrem "SEMPRE", seu posicionamento é de indiferença pela realidade social e de alienação profissional. 
CHAVES, D.E. - Posicionamento de um grupo de enfermeiros sobre o seu compromisso social. Rev. Bras. Enf.; DF, 33 : 275-304, 1980.

Após questionar-se sobre as condições de vida de grupos marginalizados de sua comunidade, você decide:

Sempre As vezes Nunca

1. Angariar fundos para cobrir as necessidades de sobrevivência da população.

2. Visitar os locais para obter informações diretas.

3. Examinar a fundo a situação para encontrar as formas de abordar os problemas.

4. Utilizar algumas horas de seu tempo disponível para junto com colegas e outros profissionais trabalhar na solução dos problemas de saúde.

5. Participar com as associaçōes ou institituições e grupos da comunidade para juntos suprirem a necessidade da população dentro de suas competências. 
CHAVES, D.E. - Posicionamento de um grupo de enfermeiros sobre o seu compromisso social. Rev. Bras. Enf.; DF, 33 : 275-304, 1980.

\section{NÍVEL DE ENVOLVIMENTO COM A COMUNIDADE DENTRO DA REALIDADE EXISTENTE}

Se você assinalou todos os itens na coluna "SEMPRE", o seu compromisso social apresenta as dimensões de: sensibilidade e conscientização dos problemas, definição de sua capacidade própria na possível solução dos problemas, decisão de agir e visão da necessidade e de forma de mobilizar os recursos.

Parabéns! Você preencheu todas estas dimensōes do compromisso social, está realmente comprometido!

Se, porém, você assinalou nas colunas "AS VEZES" ou "NUNCA", leia as explicaçōes dos itens, tomados isoladamente, para situar-se em relação ao compromisso social.

Respostas 1, 2, 3:

Seu comprometimento está a nível de ações individuais.

Se marcou resposta 1 , você está inclinado às açōes caritativas.

Se marcou respostas 2 a 3 , você está inclinado a uma atitude científica de análise de problemas.

Respostas 4 a 5 :

Seu comprometimento está a nivel de açōes de grupo.

Se marcou resposta 4, você está inclinado a agir como representante da classe profissional.

Se marcou resposta 5, você está inclinado a agir como representante do contexto social. 
CHAVES, D.E. - Posicionamento de um grupo de enfermeiros sobre o seu compromisso social. Rev. Bras. Enf.; DF, 33 : 275-304, 1980.

Em situações de calamidade pública, tais como inundações ou seca em sua comunidade, você:

Sempre As vezes Nunca

1. Acompanha as notícias através dos meios de comunicação.

2. Contribui materialmente (dinheiro, roupa e alimento) para os grupos organizados com tal fim.

3. Visita os locais flagelados para obter informações diretas das necessidades.

4. Estimula a participação do sistema de saúde onde trabalha.

5. Participa da organização de grupos de voluntários para servir à população.

6. Participa da mobilização de recursos ou grupos da comunidade para suprir as necessidades da população.

7. Dedica algumas horas de seu tempo em trabalho voluntário, juntamente com outras pessoas envolvidas no atendimento de emergência.

8. Participa do trabalho com as pessoas atingidas, o tempo que for necessário até que elas descubram a maneira de superar suas dificuldades. 
CHAVES, D.E. - Posicionamento de um grupo de enfermeiros sobre o seu compromisso social. Rev. Bras. Enf.; DF, 33 : 275-304, 1980.

\section{MANIFESTAC̄ÃO DO COMPROMISSO SOCIAL EM SITUAÇÕES DE RISCO PARA A COMUNIDADE}

Se você assinalou todos os itens na coluna "SEMPRE", o seu compromisso sociaĺ em situações de emergência em sua comunidade é EXCELENTE.

Se, porém, em qualquer dos itens você assinalou nas colunas "AS VEZES" ou "NUNCA", leia as explicações dos itens quando tomados isoladamente, para situar sua atitude em relação a estas situações.

Medidas de envolvimento com a comunidade em situações de emergência:

Item 1 e 2. Dimensão de SENSIBILIZADO, equivale ao nível mínimo.

Item 3 e 4 . Dimensão de CONSCIENTIZADO, equivale ao nível médio.

Item 5 e 6. Dimensão de MOTIVADO, equivale ao nível alto.

Item 7 e 8. Dimensão de COMPROMISSO INTEGRADO, equivale ao nível máximo.

AGORA QUE VOCÊ TERMINOU O PREENCHIMENTO DESTE QUESTIONARIO, PROCEDA DA SEGUINTE MANEIRA:

1. DESTAQUE E CONSERVE PARA VOCÊ O TEXTO ANEXADO AO QUESTIONARIO.

2. COLOQUE O QUESTIONÁRIO NA URNA INDICADA, PARA FINS DE ANÁLISE GLOBAL.

O B R I G A D P E L A C OLA B O R A Ç Ã O! 